\title{
Changes in intracellular calcium concentration in bovine oocytes following penetration by spermatozoa
}

\author{
F. Z. Sun, J. P. Bradshaw ${ }^{*}$, C. Galli and R. M. Moor \\ Department of Development and Signalling, The Babraham Institute, Babraham Hall, \\ Cambridge CB2 4AT, UK
}

\begin{abstract}
The pattern of changes in intracellular calcium concentration $\left(\left[\mathrm{Ca}^{2+}\right]_{\mathrm{i}}\right)$ in bovine oocytes after penetration by spermatozoa was determined. Dynamic video imaging, using Fura-2 as a probe for intracellular free calcium, showed that activation of oocytes by spermatozoa induced multiple transient increases in $\left[\mathrm{Ca}^{2+}\right]_{\mathrm{i}}$ with a spike interval of $24.2 \pm 7.3 \mathrm{~min}$, and that the early transient increases were propagated throughout the oocytes in the form of a wave. Calcium transients at fertilization are involved in the induction of cortical granule exocytosis and the resultant block to polyspermy. The hypothesis that the inhibition of $\mathrm{Ca}^{2+}$ release from inositol trisphosphate-sensitive stores would inhibit exocytosis and increase polyspermy was tested by injecting oocytes before fertilization with heparin, a potent inhibitor of inositol trisphosphate-activated $\mathrm{Ca}^{2+}$ release. There was no significant difference after fertilization in either $\left[\mathrm{Ca}^{2+}\right]_{i}$ spikes or in polyspermy rates between control and experimental groups injected with low molecular mass heparin up to a final cytoplasmic concentration of $400 \mu \mathrm{mol} \mathrm{I}{ }^{-1}$. We conclude that inositol trisphosphate-independent $\mathrm{Ca}^{2+}$ stores may be mobilized during the fertilization of bovine oocytes.
\end{abstract}

\section{Introduction}

At fertilization, spermatozoa not only deliver DNA to the oocyte to restore diploidy, but also trigger a series of intracellular processes essential to embryogenesis. Spermatozoa activate oocytes by inducing a marked and transient change in intracellular calcium concentration $\left(\left[\mathrm{Ca}^{2+}\right]_{\mathrm{i}}\right)$ at an early stage of fertilization. In several mammalian species, sperm penetration produces transient, but periodic, $\mathrm{Ca}^{2+}$ increases that may last for several hours following the initial penetration (mice: Cuthbertson and Cobbold, 1985; Kline and Kline, 1992; hamsters: Miyazaki, 1990; pigs: Sun et al., 1992). The biological significance of the changes in $\mathrm{Ca}^{2+}$ concentration is not fully understood. However, calcium ions are known to be involved in cortical granule exocytosis which leads to a block to polyspermy and in the control of cell cycle progression (Whitaker, 1989; Miyazaki, 1990; Ozil, 1990; Kline and Kline, 1992; Sun et al., 1992).

The means by which sperm-oocyte interactions generate transient increases in $\left[\mathrm{Ca}^{2+}\right]_{\mathrm{i}}$ remain unresolved; evidence from sea urchin, hamster and mouse oocytes implicates the second messenger inositol trisphosphate $\left(\mathrm{IP}_{3}\right)$ in controlling $\mathrm{Ca}^{2+}$ release from $\mathrm{IP}_{3}$-sensitive intracellular stores (Miyazaki, 1990; Swann, 1990). However, it has been postulated that $\mathrm{Ca}^{2+}$ stores insensitive to $\mathrm{IP}_{3}$ are also mobilized at fertilization. A number of studies in sea urchin (Rakow and Shen, 1990; Crossley et al., 1991), Xenopus (Nuccitelli et al., 1993) and hamster (Miyazaki et al., 1993a) used heparin, a competitive inhibitor of $\mathrm{IP}_{3}$ -

${ }^{*}$ Correspondence.

Revised manuscript received 28 February 1994. activated $\mathrm{Ca}^{2+}$ release to distinguish between $\mathrm{IP}_{3}$-dependent and -independent $\mathrm{Ca}^{2+}$ release.

The objective of the present study was to characterize the pattern of $\left[\mathrm{Ca}^{2+}\right]_{\mathrm{i}}$ increases in bovine oocytes after fertilization, and to examine the role of $\mathrm{IP}_{3}$-induced $\mathrm{Ca}^{2+}$ release in fertilization. Understanding the activation process in bovine oocytes is of fundamental importance for parthenogenetic studies, and is particularly relevant to the process of commercial embryo multiplication by nuclear transplantation. The amount of information presently available concerning $\mathrm{Ca}^{2+}$ transients during bovine fertilization is limited. Fissore et al. (1992) showed that spermatozoa activate bovine oocytes by inducing multiple $\mathrm{Ca}^{2+}$ spikes which are analogous to those of other species. In this study, we have further characterized the dynamic pattern of $\left[\mathrm{Ca}^{2+}\right]_{\mathrm{i}}$ changes at fertilization and observed that the early transient increases are propagated throughout the cells in the form of a wave. The results obtained from oocytes injected before fertilization with heparin, to block $\mathrm{Ca}^{2+}$ release from $\mathrm{IP}_{3}$-dependent stores, suggest that $\mathrm{IP}_{3}$ independent stores may be mobilized during fertilization of bovine oocytes.

\section{Materials and Methods}

Maturation of oocytes in vitro

Bovine ovaries were obtained from a local abattoir and transported at $37^{\circ} \mathrm{C}$ in PBS. Intact, non-atretic follicles (3-8 mm in diameter) were dissected from the ovaries in PBS and opened to remove the entire cumulus-oocyte complex into Medium 199 (Gibco, Paisley). 
Groups of 30-50 cumulus-enclosed oocytes were washed and then transferred to $30 \mathrm{~mm}$ plastic dishes containing $2 \mathrm{ml}$ Medium 199, supplemented with $20 \%$ heat-inactivated steer serum (Globe Pharmaceuticals, Esher, Surrey) and with additional granulosa cells from a freshly prepared non-atretic follicle. Maturation was performed non-statically at $38.5^{\circ} \mathrm{C}$, in $5 \% \mathrm{CO}_{2}$ in air, for $23-24 \mathrm{~h}$.

\section{In vitro fertilization procedures}

The procedures and media used for fertilization of bovine oocytes in vitro were essentially those of Parrish et al. (1988). Frozen-thawed bovine spermatozoa, obtained from a single bull ejaculate and stored under liquid $\mathrm{N}_{2}$, were washed twice by centrifugation at $800 \mathrm{~g}$ for $5 \mathrm{~min}$ in a calcium-free modified Tyrode's medium (sperm-TALP) and then resuspended at a concentration of $1 \times 10^{6}$ spermatozoa ml ${ }^{-1}$ in calcium-containing TALP (fert-TALP). Drops $(50 \mu \mathrm{l})$ were established under liquid paraffin oil (BDH, Lutterworth, Leicestershire). Oocytes were washed twice in low bicarbonate $\left(2 \mathrm{mmol} \mathrm{l}^{-1}\right)$-TALP buffered with Hepes $\left(20 \mu \mathrm{mol} \mathrm{l}^{-1}\right)$.

Certain experiments required the oocytes to be totally denuded of cumulus cells before fertilization and this was carried out mechanically by gentle pipetting.

\section{Measurement of intracellular calcium}

Oocytes were labelled, either before or after insemination, with the calcium-sensitive fluorescent dye fura-2 acetoxy methylester (Fura-2; Sigma, Poole; $4 \mu \mathrm{mol} \mathrm{l}{ }^{-1}$ ) in fert-TALP for $30-90 \mathrm{~min}$ at $38.5^{\circ} \mathrm{C}$. They were then gently washed three times in TALP.

The subsequent method and conditions for calcium measurement, together with dynamic video imaging procedures were as described by Neylon et al. (1990). Fura-2 fluorescence was measured using a Nikon inverted epifluorescence microscope. A rotating filter wheel and a shutter apparatus were used to alternate excitation wavelengths of $340 \mathrm{~nm}$ and $380 \mathrm{~nm}$ with a band width of $12 \mathrm{~nm}$. Dose was attenuated with a series of neutral density filters. The time between measurements varied between 2 and $20 \mathrm{~s}, 240 \mathrm{~ms}$ being the exposure time for each datum point. Ratios $(340 \mathrm{~nm}: 380 \mathrm{~nm})$ of 0.30 and 1.82 were estimated to correspond to $\left[\mathrm{Ca}^{2+}\right]_{i}$ of $0 \mathrm{nmol} \mathrm{l}^{-1}$ and $1000 \mathrm{nmol} \mathrm{l}^{-1}$, respectively.

\section{Microinjection of oocytes before insemination}

The preparation and assembly of microinstruments and manipulation chamber were as described by Sun (1989). Injection pipettes were used with an inner diameter of 3-5 $\mu \mathrm{m}$. Each oocyte was held with a holding pipette (overall diameter $120 \mu \mathrm{m})$ and injected with $10 \mathrm{pl}$ ( $1 \%$ of oocytes volume) of either injection solution (as control) or low relative molecular mass heparin ( $M_{\mathrm{r}}$ 3500; Sigma). The heparin was dissolved in the injection solution which contained the following: $0.9 \%$ $\mathrm{NaCl} ; 0.01 \mathrm{mmol}^{\mathrm{EDTA} \mathrm{I}}{ }^{-1} ; 1.0 \mathrm{mmol}^{\text {Tris } \mathrm{l}^{-1}}, \mathrm{pH} 7.2$. All manipulation procedures were performed in microdrops $(5 \mu \mathrm{l})$ of $\mathrm{Ca}^{2+}$-free PBS covered by light liquid paraffin oil. After injection, oocytes were washed in low-bicarbonate TALP before insemination.

\section{Incubation with BAPTA-A/M}

As a control for experiments using heparin, oocytes were incubated with BAPTA-A/M (Sigma), a highly specific calcium chelator. BAPTA-A/M contains a hydrophobic acetoxymethyl moiety which allows the uptake of BAPTA-A/M into the cell which is then cleaved by esterases, trapping BAPTA molecules within the cell.

Metaphase II oocytes ( $22 \mathrm{~h}$ maturation) were incubated for $1 \mathrm{~h}$ at $38.5^{\circ} \mathrm{C}, 5 \% \mathrm{CO}_{2}$ in BAPTA-A/M $\left(25 \mu \mathrm{mol} \mathrm{l}^{-1}\right)$ in DMSO, washed several times and incubated for $1 \mathrm{~h}$ before fertilization. Control oocytes were similarly treated with DMSO.

\section{Assessment of cytology}

Groups of oocytes at various stages after insemination were fixed for a minimum of $24 \mathrm{~h}$ in ethanol:acetic acid (3:1, v:v), stained with aceto-orcein (BDH) and assessed for sperm penetration and nuclear morphology using phase contrast microscopy.

\section{Results}

\section{Optimization of Fura-2 labelling of bovine oocytes}

Preliminary experiments involved labelling freshly matured bovine oocytes with Fura-2 $\left(4 \mu \mathrm{mol} \mathrm{l}{ }^{-1}\right)$ for $60-90 \mathrm{~min}$ in the same manner as that used successfully for pig oocytes (Sun et al., 1992). However, bovine oocytes appeared to be more sensitive than were pig oocytes and, although sperm entry was not inhibited, the intracellular level of calcium became markedly and permanently increased $5 \mathrm{~h}$ after treatment. Furthermore, the presence of cumulus cells around bovine oocytes was found to interfere with the measurement of $\left[\mathrm{Ca}^{2+}\right]_{i}$. The required Fura- 2 labelling conditions finally defined by experimentation for the measure of free $\mathrm{Ca}^{2+}$ in bovine oocytes used mechanically denuded oocytes incubated with $4 \mu \mathrm{mol}$ Fura-2 $1^{-1}$ for $30 \mathrm{~min}$ immediately before image analysis.

Fertilization and monospermy rates of control, denuded and Fura-2-labelled denuded oocytes are given (Fig. 1). Fertilization rates, as judged by pronuclear formation, were not affected by denuding oocytes before insemination or by incubation with Fura-2. Polyspermy rates were very low (about 10\%), indicating that observed changes in $\left[\mathrm{Ca}^{2+}\right]_{\mathrm{i}}$ (see next section) are the result of penetration by a single spermatozoon. Experiments in which groups of oocytes were fixed and stained at intervals of $1 \mathrm{~h}$ showed that the majority were penetrated $4-6 \mathrm{~h}$ after insemination.

\section{Measurement of $\left[\mathrm{Ca}^{2+}\right]_{i}$ changes in oocytes following fertilization}

Groups of oocytes were labelled with Fura-2 at different times $(0-6 \mathrm{~h})$ after insemination and the changes in their $\left[\mathrm{Ca}^{2+}\right]_{i}$ concentrations were examined by dynamic imaging. 


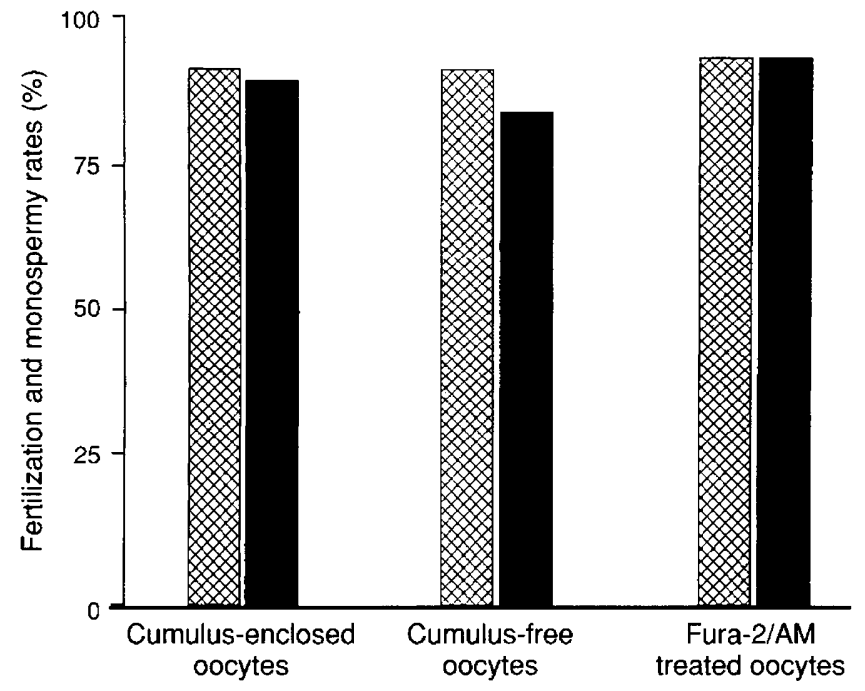

Fig. 1. Overall fertilization (国) and monospermy ( $\boldsymbol{G}$ ) rates of control (cumulus-enclosed) bovine oocytes compared with cumulus-free and Fura-2-treated oocytes. Duration of Fura-2 treatment was $60 \mathrm{~min}$.

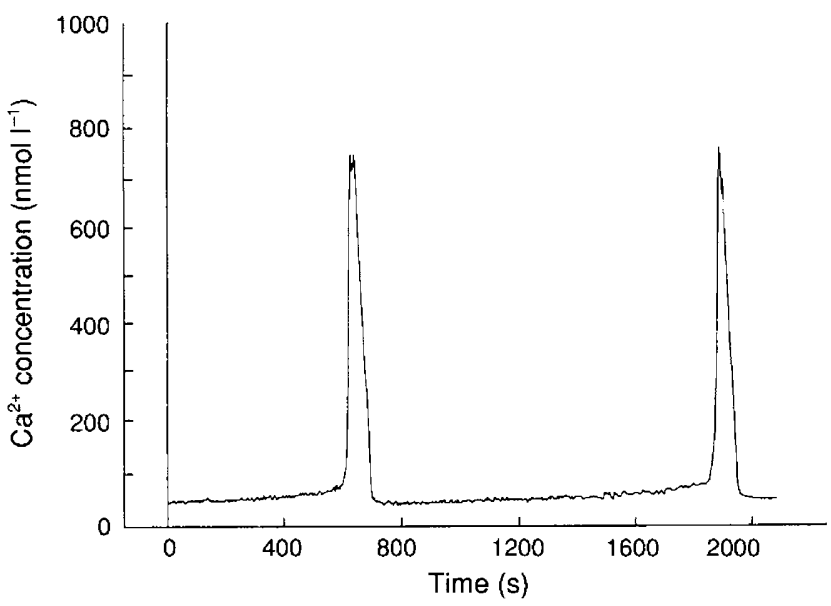

Fig. 2. An example of the pattern of the first two transient increases in $\left[\mathrm{Ca}^{2+}\right]_{i}$ in a bovine oocyte undergoing fertilization.

Individual oocytes were examined for the presence of spiking and, if spiking was detected, were studied for $2-3 \mathrm{~h}$. Certain oocytes failed to show transients, probably owing to the cessation of their period of calcium change.

The results show that, before sperm penetration, the oocyte basal $\left[\mathrm{Ca}^{2+}\right]_{i}$ remained consistently low (in the range $\left.30-140 \mathrm{nmol} \mathrm{I}^{-1}\right)$. Transient $\left[\mathrm{Ca}^{2+}\right]_{\mathrm{i}}$ increases were observed only in oocytes penetrated by spermatozoa; an example of the pattern of changes is shown (Fig. 2).

Analysis of the dynamic pattern of individual oocytes following activation by spermatozoa from a homogeneous population is summarized (Table 1 ). During the first $9 \mathrm{~h}$ after insemination (about $3-5 \mathrm{~h}$ after sperm penetration), the number of calcium spikes per oocyte observed was $2.8 \pm 1.6$ (mean $\pm \mathrm{SD}, n=12$ oocytes). The range was from $I$ to 5 spikes. Among the twelve oocytes characterized, the percentage showing 1, 2, 3, 4 or 5 spikes was 33.3, 16.7, 8.3, 16.7 and 25.0, respectively. Before each spike, there was always a gradual increase in basal $\left[\mathrm{Ca}^{2+}\right]_{\mathrm{i}}$; a spike was initiated only when this reached a threshold value of between 150 and $200 \mathrm{nmol}^{-1}$. The interval between spikes was $24.3 \pm 7.3 \mathrm{~min} \quad(n=12$ oocytes). The peak $\left[\mathrm{Ca}^{2+}\right]_{\mathrm{i}}$ achieved was $487.3 \pm 141.0 \mathrm{nmol}$ $1^{-1}(n=12$ oocytes), but there was a large variation in the peak $\left[\mathrm{Ca}^{2+}\right]_{i}$ observed in oocytes of different experimental groups. It appeared that the first $\mathrm{Ca}^{2+}$ spike achieved tended to be slightly greater in amplitude than subsequent ones. The time taken for an oocyte to achieve a peak $\left[\mathrm{Ca}^{2+}\right]_{\mathrm{i}}$ from a threshold value was $66.1 \pm 20.8 \mathrm{~s}(n=12)$; this was similar to the time taken to then decline to threshold values.

Video imaging of $\left[\mathrm{Ca}^{2+}\right]_{i}$ changes of an oocyte (Fig. 3) indicated that the transient rise is initiated at a single site within the oocyte and is then propagated throughout the cell in the form of a wave.

After video imaging, oocytes were returned to culture and fixed at approximately $16 \mathrm{~h}$ from the start of insemination. Oocytes exhibiting spikes, and the majority of those without, had undergone fertilization as evidenced by the presence of two pronuclei.

\section{Antagonism of $I P_{3}$-sensitive calcium release by heparin}

In this part of the study we examined the possibility that the inhibition of $\mathrm{Ca}^{2+}$ release from $\mathrm{IP}_{3}$-sensitive stores in bovine oocytes would block exocytosis and consequently increase the rate of polyspermy. Denuded bovine oocytes were microinjected immediately before fertilization with heparin, yielding a final cytoplasmic concentration of $100-400 \mu \mathrm{mol} \mathrm{l}^{-1}$. However, not only were fertilization rates consistently high $(>85 \%)$, but the proportions of monospermic and polyspermic eggs in control and heparin-injected groups were statistically indistinguishable (Table 2). Moreover, cytological assessment showed that the majority of polyspermic oocytes in control and treated groups were penetrated by only two spermatozoa and that none contained more than four spermatozoa.

In contrast, incubation with BAPTA-A/M induced a high level of polyspermy; the number of spermatozoa penetrating the oocyte ranged from two to seven. Oocytes remained at metaphase II stage and the second polar body was not extruded.

Video imaging showed that during the first $9 \mathrm{~h}$ after insemination four of the twenty heparin-injected oocytes examined showed $1-2\left[\mathrm{Ca}^{2+}\right]_{i}$ spikes.

\section{Discussion}

The study reported here established that in bovine oocytes sperm penetration causes the generation of multiple transient increases in intracellular calcium. Although the general pattern of $\left[\mathrm{Ca}^{2+}\right]_{\mathrm{i}}$ transients is similar to that of other species (see Sun et al., 1992 for references), bovine oocytes exhibit a characteristic pattern both with respect to spike amplitude and spiking interval. In mice and hamsters, the first increase in $\left[\mathrm{Ca}^{2+}\right]_{\mathrm{i}}$ occurs immediately after insemination (Miyazaki et al., 1989; Kline and Kline, 1992), whereas in cows several hours elapse before the first transient. Two factors contribute to this delay. First, the time required for sperm capacitation is longer in cattle than in 


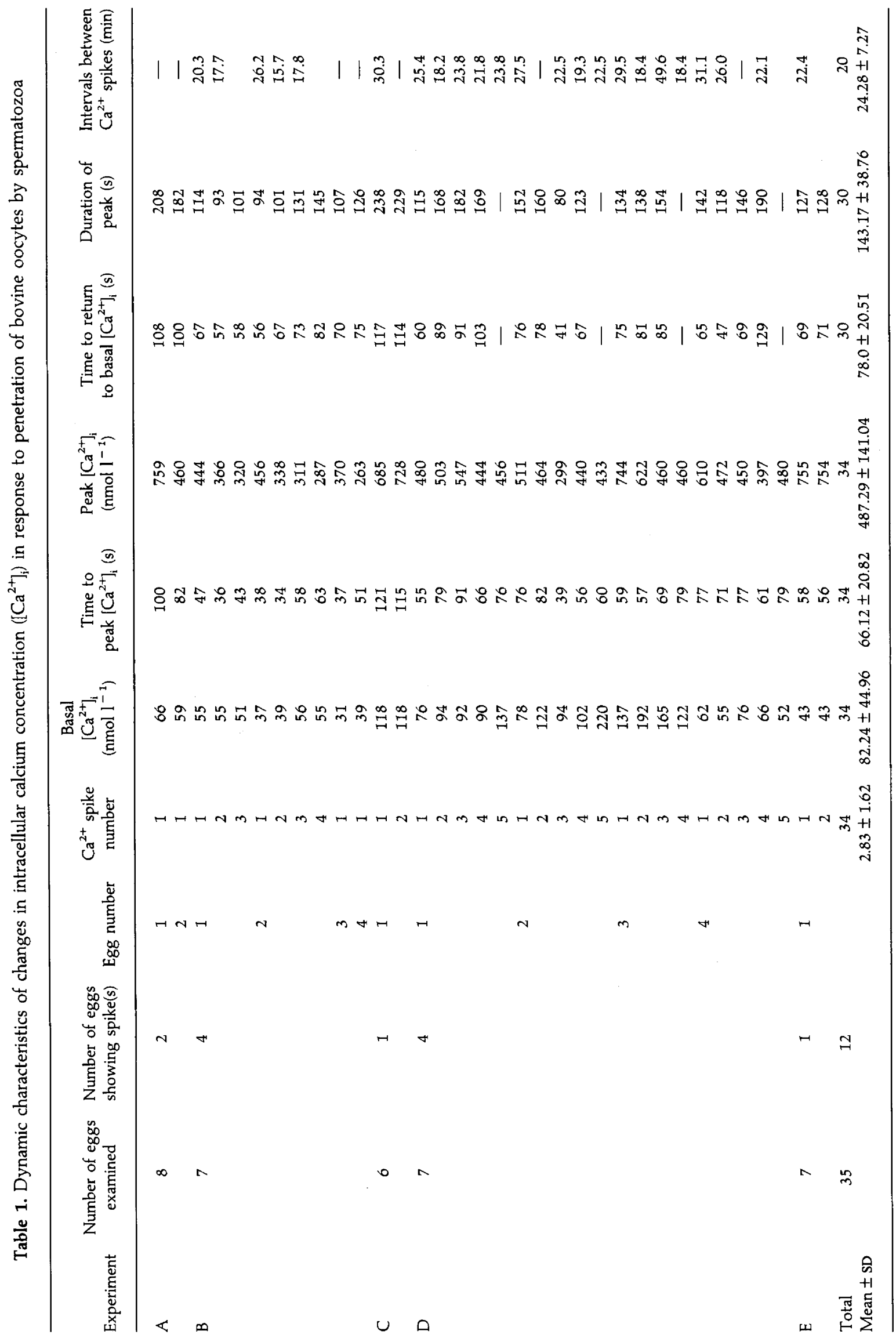




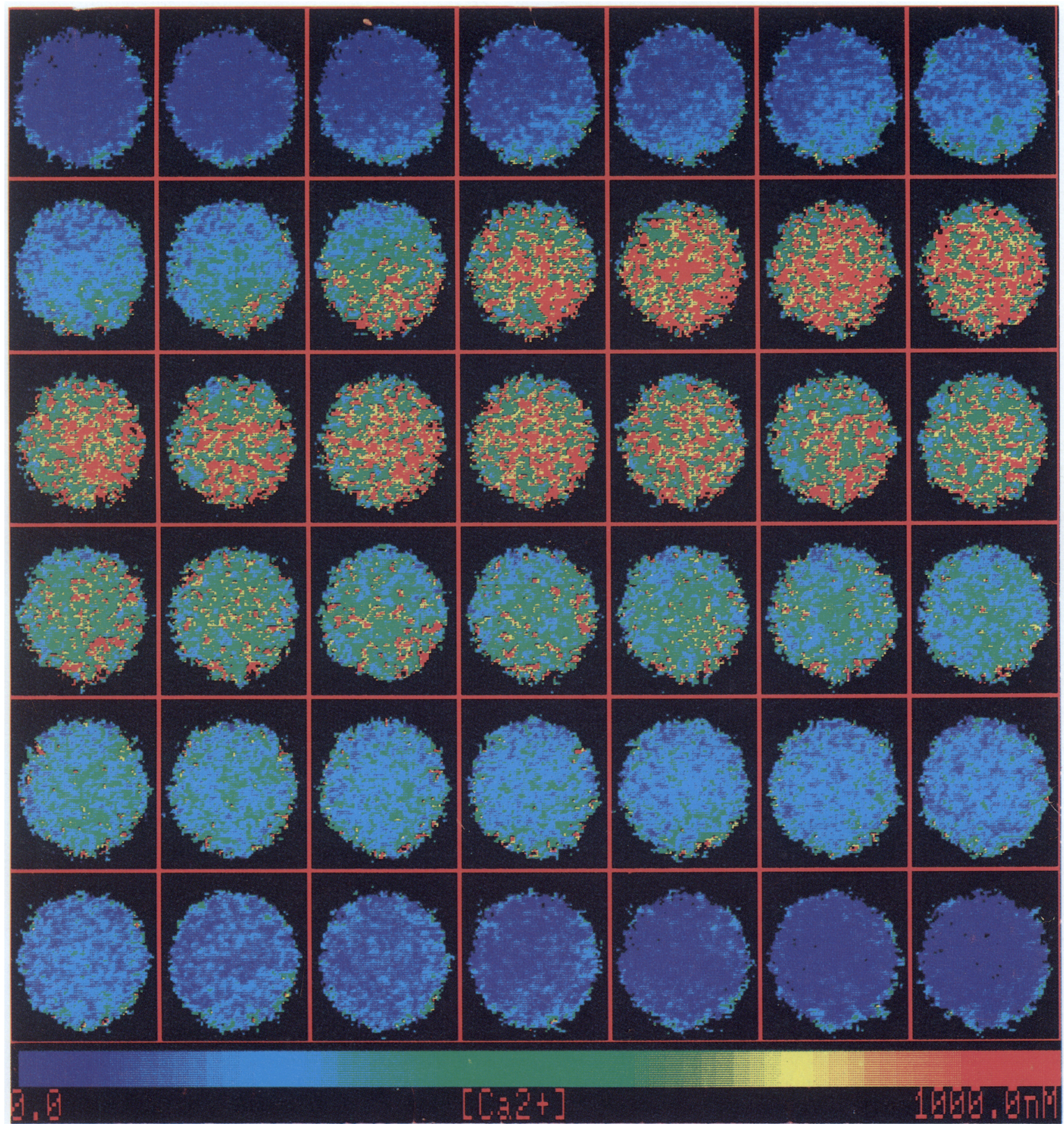

Fig. 3. Pseudo-coloured $\mathrm{Ca}^{2+}$ images trom the rising phase of the initial $\left|\mathrm{Ca}^{2+}\right|_{i}$ transient in a bovine oocyte undergoing fertilization. Frane interval: $2.2 \mathrm{~s}$

other species studied. Second, the time for sperm penetration in mouse and hamster oocytes has been reduced by the use of zona-free oocytes. In addition to these technical differences, clear species-related spiking patterns wore observed. Thus, after penctration bovine oocytes show a much longer spiking interval than did either mouse or hamster oocytes (Miyazaki et il, 1989; Kline and Kline, 1992). However, spiking intervals in bovine oocytes are reasonably similar to those of pig oocytes (Sun et al., 1992). The differences in the spiking interval may reflect the varying efficiency with which the second messenger systems regulate $\left[\mathrm{Ca}^{2+}\right]_{\text {, }}$ changes in oocytes of different species. In hamsters, the amplitude of the first two $\left|\mathrm{Ca}^{2+}\right|_{1}$ transients is much greater than in succeeding transients. Furthermore, the first two transients are initiated at the sitc of sperm-oocyte binding and propagate from there in the form of a wave (Miyazaki of all, 1989). Our results suggest that a 
Table 2. The rates of fertilization, monospermy and polyspermy in control and heparin-injected ${ }^{\mathrm{a}}$ groups of bovine oocytes and control and BAPTA-A/M-incubated groups of bovine oocytes

\begin{tabular}{|c|c|c|c|}
\hline Groups & & Oocytes fertilized/total (\%) & $\begin{array}{l}\text { Number of fertilized oocytes } \\
\text { that were monospermic (\%) }\end{array}$ \\
\hline \multirow[t]{2}{*}{ Control oocytes } & Denuded & $71 / 78(91)$ & $63 \quad(89)$ \\
\hline & Injected & $37 / 42(88)$ & $34 \quad(92)$ \\
\hline \multirow[t]{3}{*}{ Heparin-injected oocytes } & $100 \mu \mathrm{mol} \mathrm{l}^{-1}$ & $25 / 30(83)$ & $22 \quad(88)$ \\
\hline & $200 \mu \mathrm{mol} \mathrm{l}^{-1}$ & $41 / 48(85)$ & $36 \quad(88)$ \\
\hline & $400 \mu \mathrm{mol} \mathrm{l}^{-1}$ & $34 / 41(83)$ & $32(94)$ \\
\hline Control oocytes & DMSO $0.4 \%$ & $44 / 72(61)$ & $44(100)$ \\
\hline BAPTA-A/M-treated oocytes & $26 \mu \mathrm{mol} 1^{-1}$ & $77 / 83(93)$ & $23 \quad(30)$ \\
\hline
\end{tabular}

${ }^{2}$ Injection volume was $10 \mathrm{pl}$, equivalent to $1 \%$ of the volume of a typical bovine oocyte. Oocytes were fixed $12-15 \mathrm{~h}$ after insemination.

similar situation occurs in bovine oocytes. Video imaging revealed that the calcium wavefront commences at a single site and then travels across the whole oocyte. Owing to the presence of numerous spermatozoa surrounding the bovine oocyte after in vitro fertilization, we were unable to confirm unequivocally that the wave is propagated from the site of sperm-oocyte fusion. The wavefront travels at a velocity of approximately $2 \mu \mathrm{m} \mathrm{s}^{-1}$; the entire oocyte is traversed in approximately $1 \mathrm{~min}$. This velocity is slower than the rates in Xenopus (10 $\mathrm{m} \mathrm{s}^{-1}$ : Delisle, 1991; $7.5 \mu \mathrm{m} \mathrm{s}^{-1}$ : Nuccitelli et al., 1993) and other aquatic species (Jaffe, 1985) and much slower than in hamsters (16-28 $\mathrm{m} \mathrm{s}^{-1}$. Miyazaki et al., 1993b).

The results presented here are similar to those obtained by Fissore et al. (1992) using Fura-2-injected bovine oocytes. The penetration rates reported by Fissore et al. were low, a maximum of $56 \%$ by $16 \mathrm{~h}$. Furthermore, the wide variation in parameters, particularly interspike interval ( $15-51 \mathrm{~min}$ ) may have been, at least partially, due to the heterogeneous source of spermatozoa used. In contrast, the present work used a homogeneous sperm source and a non-invasive method of Fura-2 labelling.

The deleterious effects of ultraviolet upon oocytes during calcium measurements were minimized. The narrow band width $(12 \mathrm{~nm})$ used meant that the wavelengths used (340 and $380 \mathrm{~nm}$ ) are well-removed from the more harmful wavelengths $(254 \mathrm{~nm})$. The use of a variably rotating filter wheel and shutter apparatus minimized the exposure time of oocytes to UV, and this dose was further attenuated by neutral-density filters. The majority of oocytes, when returned to culture after analysis, showed the presence of normal male and female pronuclei.

The absence of spiking in several oocytes examined may not be significant. A likely explanation is that, when a single oocyte is studied for $2-3 \mathrm{~h}$, the period of calcium increases in other oocytes may well have passed unstudied.

It is now well established that an increase in intracellular $\mathrm{Ca}^{2+}$ at fertilization is essential for oocyte activation (Whitaker and Patel, 1990; Kline and Kline, 1992; Whitaker and Swann, 1993). However, the mechanism by which spermatozoa generate transient $\mathrm{Ca}^{2+}$ increases during oocyte activation remains unclear. It is widely acknowledged that $\mathrm{IP}_{3}$ plays an essential second messenger role in regulating $\mathrm{Ca}^{2+}$ changes at fertilization and that injection of $\mathrm{IP}_{3}$ into mammalian oocytes induces $\left[\mathrm{Ca}^{2+}\right]_{i}$ increases and cortical granule exocytosis (see Swann,
1990 for references). However, opinions differ as to whether $\mathrm{IP}_{3}$ is the sole means by which $\mathrm{Ca}^{2+}$ release (and the resultant block to polyspermy) is induced at fertilization.

The high affinity of heparin for the $\mathrm{IP}_{3}$ receptor (Ghosh et al., 1988) has been used to distinguish calcium release from $\mathrm{IP}_{3}$-regulated and $\mathrm{IP}_{3}$-independent stores. Injection of heparin into sea urchin oocytes failed to inhibit fertilization or the production of calcium spikes (Rakow and Shen, 1990; Crossley et al., 1991). However, the oocytes were polyspermic. Similar results were obtained for hamster (Miyazaki et al., 1993a) and Xenopus (Nuccitelli et al., 1993) oocytes.

The results of the experiments reported here support the concept of calcium release from multiple stores, since fertilization and the block to polyspermy were unaffected by intracellular heparin concentrations of $100-400 \mu \mathrm{mol} \mathrm{l}^{-1}$. These concentrations are considerably in excess of those used by other workers, and would appear to be adequate to compete with $\mathrm{IP}_{3}$ generated at fertilization) (less than $10 \mu \mathrm{mol}^{-1}$ (Ciapa and Whitaker, 1986; Rakow and Shen, 1990)). The existence of calcium transients in heparin-injected oocytes (one or two spikes found in four of 20 oocytes) suggests that some calcium release is independent of $\mathrm{IP}_{3}$ but the results are not conclusive.

Introduction of BAPTA into oocytes has been shown to inhibit all sperm-induced calcium transients, resulting in the inhibition of the resumption of meiosis together with polyspermy (Kline and Kline, 1992; Crossley et al., 1991). The present study obtained similar results in bovine oocytes.

These results support the concept that sperm activation may initiate calcium release from intracellular stores in bovine oocytes without the involvement of $\mathrm{IP}_{3}$, and that sufficient calcium is released to at least block polyspermy. This concept is not in agreement with that of Miyazaki et al. (1992), who used a monoclonal antibody to $\mathrm{IP}_{3}$ receptors present in hamster oocytes. At high concentrations the antibody could block sperm-induced $\left[\mathrm{Ca}^{2+}\right]_{\mathrm{i}}$ increases, suggesting the sole involvement of $\mathrm{IP}_{3}$ receptors in calcium release, and contradicting results obtained using heparin injections. Further work is required to clarify the mechanism of $\left[\mathrm{Ca}^{2+}\right]_{i}$ increases in cattle and other species.

The authors thank J. Hoyland and B. Mason for technical help in operating the imaging system. Thanks also go to B. Seamark for reading the manuscript. 


\section{References}

Ciapa B and Whitaker M (1986) Two phases of inositol polyphosphate and diacylglycerol production at fertilization FEBS Letters 195 347-351

Crossley I, Whalley T and Whitaker M (1991) Guanosine $5^{\prime}$-thiotriphosphate may stimulate phosphoinositide messenger production in sea urchin eggs by a different roufe than the fertilizing sperm Cell Regulation 2 121-133

Cuthbertson KSR and Cobbold PH (1985) Phorbol ester and sperm activate mouse oocytes by inducing sustained oscillations in cell $\mathrm{Ca}^{2+}$ Nature 316 541-542

DeLisle S (1991) The four dimensions of calcium signalling in Xenopus oocytes Cell Calcium 12 212-227

Fissore RA, Dobrinsky JR, Balise JJ, Duby RT and Robl JM (1992) Pattern of intracellular $\mathrm{Ca}^{2+}$ concentrations in fertilised bovine eggs Biology of Reproduction 47 960-969

Ghosh TK, Eis PS, Mullaney JM, Ebert CL and Gill DL (1988) Competitive, reversible, and potent antagonism of inositol 1,4,5 trisphosphate-activated calcium release by heparin Journal of Biological Chemistry 263 11075-11079

Jaffe LF (1985) The role of calcium explosions, waves and pulses in activating eggs. In Biology of Fertilization Vol. 3 pp 128-167 Eds CB Metz and A Mouroy. Academic Press, London

Kline D and Kline J (1992) Repetitive calcium transients and the role of calcium in exocytosis and cell cycle activation in the mouse eggs Developmental Biology $14980-89$

Miyazaki S (1990) Cell signalling at fertilization of hamster eggs Journal of Reproduction and Fertility Supplement 42 163-175

Miyazaki S, Whitaker MJ and Patel R (1989) Signal transduction of sperm-egg interaction causing periodic calcium transients in hamster eggs. In Mechanism of Egg Activation pp 231-246 Eds R Nuccitelli, GN Cherr and WH Clark. Plenum Press, New York

Miyazaki S, Yuzaki M, Nakada K, Shirakawa H, Nakanishi S, Nakade S and Mikoshiba K (1992) Block of $\mathrm{Ca}^{2+}$ wave and $\mathrm{Ca}^{2+}$ oscillation by antibody to the inositol 1,4,5-trisphosphate receptor in fertilized hamster eggs Science $257251-255$

Miyazaki S, Nakada K and Shirakawa H (1993a) Signal transduction of gamete interaction and intracellular calcium release mechanism at fertilization of mammalian eggs. In Biology of Germ Lines in Animals and Man pp 125-143 Eds H Mohri, M. Takahashi and C Taclin. Japan Scientific Society Press, Tokyo

Miyazaki S, Shirakawa H, Nakada K and Honda Y (1993b) Essential role of the inositol 1,4,5-trisphosphate receptor/ $/ \mathrm{Ca}^{2+}$ release channel in $\mathrm{Ca}^{2+}$ waves and $\mathrm{Ca}^{2+}$ oscillations at fertilization of mammalian eggs Developmental Biology 158 62-78

Neylon CB, Hoyland J, Mason WT and Irvine RF (1990) Spatial dynamics of intracellujar calcium in agonist-stimulated vascular smooth muscle cells American journal of Physiology 259 C675-C686

Nuccitelli R, Yim DL and Smart T (1993) The sperm-induced calcium wave following fertilization of the Xenopus egg requires the production of Ins $(1,4,5) \mathrm{P}_{3}$ Developmental Biology 158 200-212

Ozil JP (1990) The parthenogenetic development of rabbit oocytes after repetitive pulsatile stimulation Development 109 117-127

Parrish JJ, Susko-Parrish J, Winer MA and First NL (1988) Capacitation of bovine sperm by heparin Biology of Reproduction 38 1171-1180

Rakow TL and Shen SS (1990) Multiple stores of calcium are released in the sea urchin egg during fertilization Proceedings of the National Academy of Sciences, USA $879285-9289$

Sun FZ (1989) Nuclear-Cytoplasmic Interactions During Oocyte Maturation and Early Embryogenesis in Sheep. PhD Thesis, Cambridge University, UK

Sun FZ, Hoyland J, Huang X, Mason W and Moor RM (1992) A comparison of intracellular changes in porcine eggs after fertilization and electroactivation Development 115 947-956

Swann K (1990) A cytosolic sperm factor stimulates repetitive calcium increases and mimics fertilization in hamster eggs Development 1101295 1302

Whitaker M (1989) Phosphoinositide second messages in eggs and oocytes. In Inositol Lipids in Cell Signalling pp 459-483 Eds RH Michell, AH Drummond and CP Downes. Academic Press, London

Whitaker MJ and Patel R (1990) Calcium and cell cycle control Development $108525-542$

Whitaker MJ and Swann K (1993) Lighting the fuse at fertilization Development 117 1-12 